\title{
CMR of LV non-compaction cardiomyopathy: association of clinical presentation and prognosis with cardiac phenotype
}

\author{
Mushabbar A Syed ${ }^{1 *}$, Steve W Leung ${ }^{2}$, Samy Claude Elayi ${ }^{3}$, Richard J Charnigo Jr. ${ }^{3}$ \\ From 2011 SCMR/Euro CMR Joint Scientific Sessions \\ Nice, France. 3-6 February 2011
}

\section{Background}

Left ventricular non-compaction (LVNC) is a rare congenital disorder characterized by two layered myocardium; trabeculated (non-compacted) and a non-trabeculated (compacted). LVNC is increasingly being recognized due to better imaging technology as a cause for heart failure and sudden cardiac death; however, data on clinical and imaging characteristics remains limited.

\section{Objective}

To investigate the association of clinical presentation and outcomes in LVNC with cardiac phenotype by CMR.

\section{Methods}

Fourteen patients (mean age $33.1 \pm 17.6$ years, 9 male) were retrospectively identified from CMR database between December 2007 and May 2010. CMR imaging included SSFP cine in standard views and late gadolinium enhancement. Quantitative analysis included left and right ventricular function, volumes, mass, LV wall motion score and non-compacted to compacted myocardium $(\mathrm{NC} / \mathrm{C})$ ratios in different segments. Number of involved LV segments and regions of maximum $\mathrm{NC} / \mathrm{C}$ ratio were also recorded.

Patient's medical records were reviewed for clinical history including NYHA functional class, ECG, telemetry, Holter/event monitoring and electrophysiology studies.

Non-parametric $U$ test, logistic regression analysis and parametric T-test were used to determine statistical significance as appropriate.

${ }^{1}$ Loyola University, Stritch School of Medicine, Maywood, IL, USA

Full list of author information is available at the end of the article

\section{Results}

Seven patients presented with acute heart failure including one in cardiogenic shock. Three patients presented with syncope, one with documented ventricular tachycardia (VT).

Mean LVEF was $36.2 \pm 22.8 \%$ and mean RVEF $31.5 \pm$ $16.7 \%$. LVEF $<50 \%$ was present in 8 patients $(57.1 \%)$, RVEF $<40 \%$ in $7(50 \%)$ and both in $6(42.8 \%)$ patients. Mean NC/C myocardium ratio was $3.7 \pm 0.8$ with mean of 5.5 $\pm 3.1 \mathrm{LV}$ segments involved. Patients with LV dysfunction were older, more symptomatic with higher NYHA class, had more myocardial segments involvement with non-compaction, and higher $\mathrm{NC} / \mathrm{C}$ ratios (Table 1). No myocardial infarction or mid-wall fibrosis was seen on late gadolinium enhancement. One patient had thrombus in the right ventricle associated with severe RV dysfunction.

Four patients had non-sustained monomorphic VT. Two patients had premature ventricular complexes on

\section{Table 1}

\begin{tabular}{llll}
\hline & $\begin{array}{l}\text { LVEF }>\mathbf{5 0 \%} \\
(\mathbf{N}=\mathbf{6})\end{array}$ & $\begin{array}{l}\text { LVEF } \leq \mathbf{5 0 \%} \\
\mathbf{( N = 8 )}\end{array}$ & $\begin{array}{l}\mathbf{p}- \\
\text { value }\end{array}$ \\
\hline Age & $21.6 \pm 11.0$ & $42.5 \pm 16.6$ & 0.008 \\
NYHA class & $1(\mathrm{IQR} 1-1)$ & $3(\mathrm{IQR} 2-4)$ & 0.007 \\
$\begin{array}{l}\text { LV end-diastolic volume index } \\
\left(\mathrm{ml} / \mathrm{m}^{2}\right)\end{array}$ & $96.1 \pm 15.3$ & $155.4 \pm 36.6$ & 0.001 \\
$\mathrm{LV} \mathrm{end-systolic} \mathrm{volume} \mathrm{index}$ & $38.6 \pm 7.5$ & $129.6 \pm 38.2$ & $<0.001$ \\
$\left(\mathrm{ml} / \mathrm{m}^{2}\right)$ & & & \\
LV mass index $\left(\mathrm{g} / \mathrm{m}^{2}\right)$ & $55.4 \pm 8.5$ & $80.2 \pm 17.3$ & 0.004 \\
Wall motion score index & $1.0 \pm 0.02$ & $2.3 \pm 0.3$ & $<0.001$ \\
Non-compacted segments & $3.8 \pm 2.1$ & $6.8 \pm 3.2$ & $<0.001$ \\
NC/C ratio (maximum) & $3.2 \pm 0.6$ & $4.1 \pm 0.8$ & $<0.001$ \\
RV EF (\%) & $44.5 \pm 6.8$ & $21.8 \pm 15.3$ & 0.002 \\
Heart failure & $0(0 \%)$ & $7(88 \%)$ & 0.005 \\
\hline
\end{tabular}


telemetry. One patient had paroxysmal atrial fibrillation, and one had atrioventricular nodal reentry tachycardia (AVNRT).

There were no deaths over a mean follow-up of $7.0 \pm$ 4.6 months. One patient received a heart transplant for severe refractory heart failure. Five patients received an ICD; 4 with non-sustained VT and 1 with severe LV dysfunction. Patient with AVNRT underwent successful ablation.

\section{Conclusion}

Patients with LVNC have a spectrum of cardiac phenotypes ranging from normal LV and RV to severe biventricular dysfunction. Clinical presentation and symptoms are associated with degree of non-compaction and ventricular dysfunction.

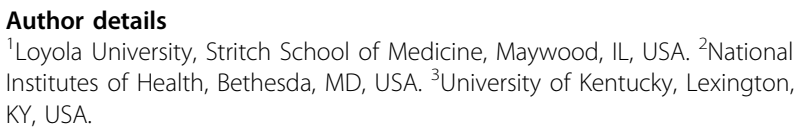

Published: 2 February 2011 